\title{
One Road: an engaging multi-touch interface within a museum context
}

\author{
Melanie Touw \\ The School of Design Studies \\ The College of Fine Arts, \\ University of New South Wales, \\ PO Box 259, Paddington, Sydney, \\ 2021, Australia \\ mel.touw@gmail.com
}

\author{
Brad Miller \\ The School of Design Studies \\ The College of Fine Arts, \\ University of New South Wales, \\ PO Box 259, Paddington, Sydney, \\ 2021, Australia \\ brad.miller@unsw.edu.au
}

\begin{abstract}
Interactive multi-touch screens in museums are often used for a dual purpose: to both educate and entertain visitors. With this in mind, how can the sense of 'delight' in the use of a multi-touch screen in a museum be explained? What kinds of 'delight' may visitors experience, and why? A case study was enacted in April 2012 on One Road, an interactive multi-touch installation in the 'Yiwarra Kuju: The Canning Stock Route' exhibition at the Australian Museum, Sydney. The study aimed to investigate user experiences of the interactive, and a range of different behaviours were observed. A discussion of the findings with reference to the concept of 'delight' in interface design examined how different aged visitors appeared to find 'delight' in different entertaining and educational features of One Road, and questioned whether entertainment-focused 'delight' was positive or negative. These considerations are important for interface designers. With further research, we may come to better understand and continue to investigate how an interface design on a multi-touch surface in a museum can be 'delightful', and influence users' experiences.
\end{abstract}

Multi-touch interface, user experiences, interactive applications, human-computer interaction, case study

\section{INTRODUCTION}

The concept of 'delight' in interface design suggests a sense of enjoyment or pleasure a user may experience when using an interface. Interactive multi-touch screens are a prime example of a technology that seems to possess an ability to generate 'delight' in its users. Direct touchbased interactions with graphical objects help facilitate more personal connections between users and interfaces. Also, the ability of the technology to detect multiple points of contact lends itself to experimentation with gestures and sharing among users. In the museum, where learning and exploration are encouraged, multi-touch screens are often deployed to both 'delight' and educate visitors.

This paper will examine the concept of 'delight' in the interface design of a specific technology, in a specific context. How may we explain a sense of 'delight' in an interface design of a multi-touch table in a museum? What kinds of 'delight' may a user experience, and what can we attribute it to? Observational research completed at the Australian Museum in April 2012 provides first-hand insights that may aid in answering these questions.

\section{RELATED WORKS}

Since Jeff Han's Frustrated Total Internal Reflection (FTIR) proposal in 2005 (Han, 2005), multi-touch technology has become more widely used in commercial products, but its integration into the Australian museum context is still quite recent. Multi-touch technology is also still fairly new (Ryall, 2006). As a result of these factors, its coverage in the Australian context remains relatively sparse.

One comprehensive source for research into multitouch technology in the Australian context is the work undertaken by the Computer Human Adapted Interaction Group (CHAl) at the University of Sydney. By constructing a series of research projects that each look at a different aspect of tabletop functionality, they are able to apply their findings to real-world projects. (Collins, et.al, 2011)

The concept of 'delight' is one that is rarely touched upon in research on multi-touch technology in the museum, with most publications focusing on the functionality, educational qualities, and effectiveness of a display. Ciocca's study of museum image collections on multi-touch tables (Ciocca, Olivo \& Schettini, 2012), Marshall's 
investigation of group participants at a multi-touch table (Marshall, et.al, 2008) and Hornecker's research into user experiences of the 'Tree of Life' table at the Berlin Museum of Natural History (Hornecker, 2008) are just three such examples.

The following research seeks to expand the topic of multi-touch technology in the Australian context, using observations of user experiences to investigate the concept of 'delight' in the use of a multi-touch interface in the museum.

\section{CASE STUDY}

A study was carried out at the Australian Museum, Sydney in April 2012. It specifically investigated visitors' experiences of information while using a multimedia installation in the 'Yiwarra Kuju: The Canning Stock Route' exhibition, by the Perth arts organisation FORM. One Road (Figure 1), a multitouch table array designed and developed by the multimedia company Lightwell, told the story of the Canning Stock Route from an Aboriginal perspective through paintings, films and narratives. It used 10 46-inch Multi-Touch Cell displays, with five Ubuntu/Linux PCs each controlling two cells. The software was created in $\mathrm{C}++$ and OpenGL, utilising the Multi-Touch Cornerstone SDK.

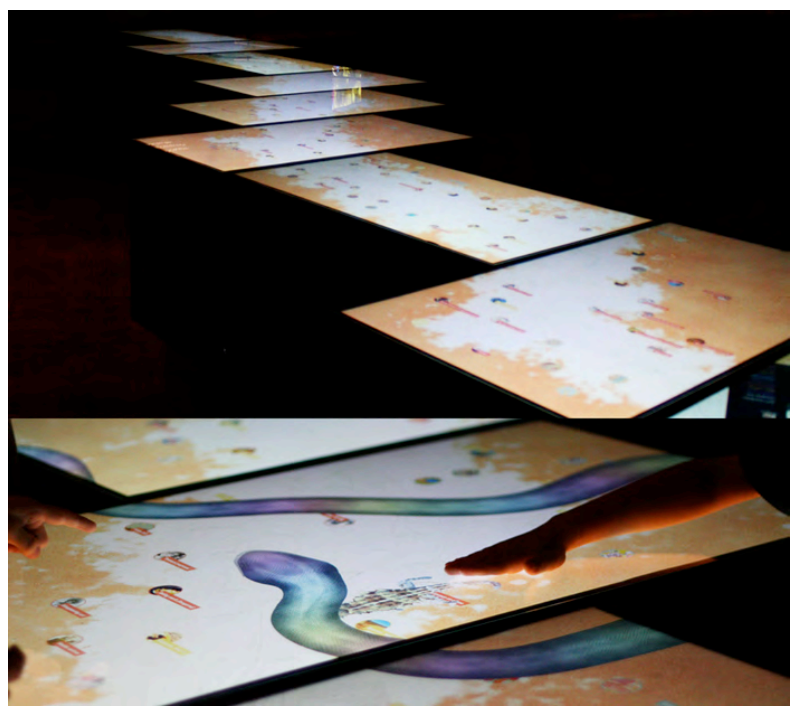

Figure 1: The One Road multi-touch interactive.

A map of the Route formed the basis for the design of an interface that presented several content nodes for visitors to expose and explore text, video, and images. Users were offered a variety of ways to interact with content using different gestures, including dragging, pinching and tapping. They could also draw in the red sand spread around the edges of the map, while a range of threedimensional animated animals were located in various positions along the table. An 'easter egg' could be found in being able to squash ants. Two painting applications were also included as a playful interactive element (Figure 2).

Six one-hour open-ended observation sessions were completed for this study. Ages and times were estimations only. The first two sessions observed the behaviours of the audience in general, and revealed several points about how users interacted with and reacted to One Road.
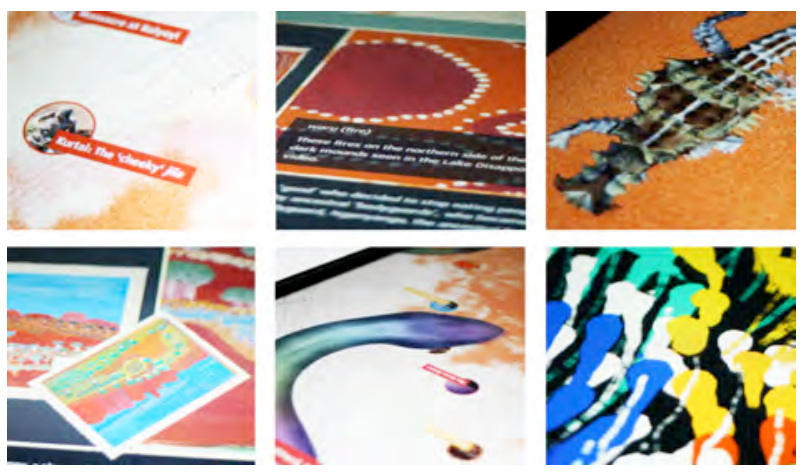

Figure 2: The various features of One Road.

Two common behaviour patterns were observed. Several people were initially hesitant in interacting with the table. However, once they tentatively touched the surface and received a response, they appeared to become more confident. This transition was often smoothed by the shared nature of the interactive - visitors could learn to interact by watching others using the table. As a result, groups used the interface effectively, helping each other interact with various elements and engaging in discussion. Due to the amount of content included in the interface, the other common behaviour pattern involved people moving slowly down the table, pausing frequently to interact with information.

Depending on their demographic, different visitors used the table in different ways. School groups from both primary and high school grades were observed, and appeared to behave in similar ways. They appeared more interested in the playful interactive elements than the information-based content, and seemed fascinated with the interactive functions of the multi-touch surface, often working together by interacting as a group with various images, as well as the painting application. The only difference between the primary and high school groups was that the high school group participated in more detailed discussion about the table itself. Otherwise, children in general only took note of specific content when parents or teachers drew their attention to it.

The behaviours of adults, on the other hand, were mixed. Some adults spent considerable time reading and watching content, while others only glanced at the table before moving away. Parents 
with children would often separate into two groups. Children played with various interactive elements, while their parents became immersed in the content. Children also sometimes showed their parents or guardians how to interact with One Road. Older people appeared to prefer looking to touching, and seemed quite hesitant to interact.

The design of the interface itself was simple. Breaking the large amount of content into chunks for users to explore made the information easier to absorb, and allowed users to reveal as much or as little as they wished. The interface was also quite shallow, with only three exposable levels (the top level map with content nodes, information windows, and image break-outs). Visual information dominated the interface, accompanied by brief descriptions and narratives.

The third, fourth, fifth and sixth sessions investigated aspects of the behaviours of particular visitors. Observation sheets were filled out, while photographs were taken for documentation. 136 people in total were observed in these last four sessions. These observations examined a mix of visitors - school children to the elderly - and noted whether visitors interacted as an individual or in a group. The first point of contact for most users was predominantly at either end of the table. Visitors were equally as likely to explore three screens as they were to explore 10 screens. The average time spent by users was one to two minutes, although the longest time spent was 23 minutes. The most used gestures were first finger and middle finger touches, while the zoom/rotate gestures were less used. The most exposed types of media were images, text, and sand drawing.

\section{DISCUSSION OF FINDINGS}

The observation sessions revealed a variety of points about the behaviour of users toward One Road. From these findings, we may begin to answer questions about 'delight' in interface design on a multi-touch table in the museum.

As stated, multi-touch technology in general can elicit 'delight' in its users due to its ability to support multiple users and encourage exploration. While single-touch screens only accommodate one user at a time, multi-touch allows multiple visitors to interact simultaneously, using their hands instead of intermediary tools such as keyboards or mice. This slightly more 'natural' method of interaction seems to be enjoyable for users, smoothing the connections between visitors and information in the museum.

This paper has already discussed multi-touch technology in general and its effect on users' enjoyment, but the way in which both design and technology intersect to create 'delightful' experiences is paramount. Without a well-designed interface, display technology is useless. In One Road, by breaking up the content and giving users the freedom to select which sections to explore, a more enjoyable experience is created. The animated interactive elements contribute to this experience. The interactive is able to respond in a variety of ways, not only providing information to users but also recreation.

The inclusion of both entertaining and educational features in an interactive table is a significant factor in this discussion. What kinds of 'delight' can be experienced by visitors, and why? Is there a difference between the enjoyment of playful interactive elements and the enjoyment of information? The observations showed that different aged visitors experienced 'delight' in interacting with different features of One Road. Children, for example, appeared highly interested in the playful features of the table, zooming into images (Figure 3), pointing out the Rainbow Serpent, and using the painting application. Adults, on the other hand, were more inclined to expose, read and discuss content. These observations indicate that perhaps interfaces can evoke different kinds of 'delight' in users, which may be dependent on their age. Children seem to find delight in play and interactivity, while adults appear to be more interested in what they can learn.

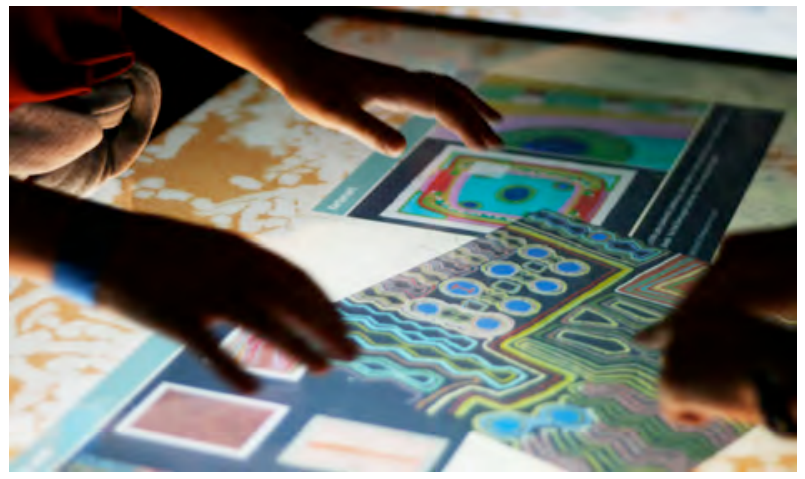

Figure 3: Children zooming into images.

This leads to the question of whether 'delightful' interfaces on interactive multi-touch screens are effective in museums. The observations of One Road showed that due to their preoccupation with the interactive qualities of the table, children rarely navigated to the actual content within the interface. Their sense of 'delight' in using the interactive features distracted them from the educational elements of One Road, despite the simple, easy-touse interface and well-proportioned pieces of content. In this sense, although multi-touch technology does encourage sharing and exploration, its responsiveness also creates a kind of 'spectacle', which some users seem fascinated 
by. For a public space such as the museum, where learning is an important goal, balancing education and entertainment can be a real problem.

Future developments of multi-touch technology could change how we may investigate 'delight' in interface design in the museum context. They could also solve certain issues, such as the balance between education and entertainment. A number of Australian museums have been investigating how mobile interactive devices may be used in an exhibition context (Styles, 2011). $\mathrm{CHAI}$, as mentioned previously, recently completed research at the Australian Museum on using iPads and multi-touch tables together to facilitate the learning experiences of students. (Collins, et.al., 2012) In the study, users carried an iPad around an exhibition and collected data. They then returned to a multi-touch table, where their data could be assembled into a poster to be taken back to the classroom.

A large-scale installation such as One Road could benefit from this approach. If users had a more specific task to complete at the table, visitors particularly children - may then become more focused on learning, without taking away the 'delightful' interactive qualities of the installation. Specifically, it could translate a user's experience from delight in play to delight in finding or learning about relationships.

While this is only one potential path that multi-touch technology in the museum - and One Road - could take, it demonstrates how future developments of multi-touch could change the ways in which users absorb information and experience 'delight' in different uses of the technology.

\section{CONCLUSION}

The issues evoked by this discussion reinforce the need for the changing role of interactive technologies in museums - and the ways in which different visitors find 'delight' in their use - to be constantly questioned and reconsidered. Specifically, how may designers address the lack of balance between entertainment and learning? Both the designer and the museum (educationalists) must thoughtfully define the purpose of an interactive within an exhibition context - what kind of role does it play in a user's learning experience?

Furthermore, in One Road, the playful interactive elements and educational content layers were quite separate. If these elements were more integrated, such as using playful features to lead to or highlight certain content, rather than operating on separate levels, a better balance could be achieved, leading to increased engagement with educational content.
Overall, One Road seems to tread the line between 'delight' in the use of a well-designed interface, and 'delight' in the interactive qualities of a technology. As new ways of deploying multi-touch interactive technologies emerge - such as integrating mobile devices and multi-touch tables - more issues will undoubtedly emerge. Additional future research into user experiences of multi-touch interfaces in museums will help to expand this topic and generate more insightful results.

\section{REFERENCES}

Ciocca, G., Olivo, P., Raimondo, S. (2012) Browsing museum image collections on a multitouch table. Information Systems, vol.37, pp.169182.

Collins, A.. 'Core functionality and new applications for tabletops and interactive surfaces', in

Proceedings of UbiComp '11, Beijing, China, 17-21 September 2011, pp. 607-608.

Collins, A., Clayphan, A., Kay, J., and Horder, J. (2012) My museum tour: Collaborative poster creation during school museum visits. In Educational Interfaces, Software, and Technology 2012: 3rd Workshop on UI Technologies and Educational Pedagogy, Austin, Texas, USA, 5-6 May 2012, pp.1-4.

Han, J.Y. (2005) Low-cost multi-touch sensing through frustrated total internal reflection. Proceedings of the $18^{\text {th }}$ Annual ACM Symposium on User Interface Software and Technology, UIST'05, ACM, New York, NY, USA, 2005, pp.115118.

Hornecker, E. "I don't understand it either, but it is cool" - Visitor interactions with a multi-touch table in a museum. Proceedings of the 2008 IEEE International Workshop on Horizontal Interactive Human Computer System (TABLETOP), Amsterdam, The Netherlands, 1-3 October 2008, pp. 113-120.

Marshall, P., Hornecker, E., Morris, R., Sheep Dalton, N., and Rogers, Y. (2008) When the fingers do the talking: A study of group participation with varying constraints to a tabletop interface. Proceedings of the 2008 IEEE International Workshop on Horizontal Interactive Human Computer System (TABLETOP), Amsterdam, The Netherlands, 1-3 October 2008, pp.33-40.

Ryall, K., Morris, M.R., Everitt., K., Forlines, C., and Shen, C. (2006) Experiences with and observations of direct-touch tabletops. Proceedings of the First IEEE International Workshop on Horizontal Interactive Human-Computer Systems, Adelaide, Australia, 5-7 January 2006.

Styles, C. (2011) Museum's iPad game creates world. National Museum of Australia. Available from http://nma.gov.au/blogs/education/ 2011/12/02/create-world/ (30 July 2012) 